КИПКЕЕВ Таулан Муратович - аспирант департамента политологии и массовых коммуникаций Финансового университета при Правительстве РФ (125993, Россия, г. Москва, ГСП-3, Ленинградский np-кm, 49; kipkeev_finuniversitet@mail.ru)

\title{
ВЗАИМОДЕЙСТВИЕ ВЛАСТИ И БИЗНЕСА В СОВРЕМЕННОЙ РОССИИ: АНАЛИЗ ПРАКТИК СУБЪЕКТОВ РОССИЙСКОЙ ФЕДЕРАЦИИ
}

\begin{abstract}
Аннотация. В статье рассматриваются особенности и формы взаимодействия власти и бизнеса в региональном аспекте. Автор выявляет ключевые проблемы и перспективные направления развития взаимодействия региональной власти и бизнеса.

Ключевые слова: бизнес, бизнес-инкубатор, государственная программа, государственно-частное партнерство, государственные закупки, коррупция, малое и среднее предпринимательство, налоговая нагрузка
\end{abstract}

П ереход политической системы России к новым условиям государственного и общественного развития способствовал формированию в нашей стране более разнообразных и устойчивых форм взаимодействия бизнеса и органов государственной власти. Будучи самостоятельным элементом гражданского общества, бизнес и его представители в лице предпринимателей и руководителей организаций, с одной стороны, дистанцированы от государства, с другой - зависимы от властных решений государственных, в т.ч. региональных, органов власти. В литературе отмечается взаимная заинтересованность и взаимная ответственность предпринимателей и органов государственной власти, поскольку решение политических задач определяется существующими в стране темпами экономического роста, которые в последние годы далеки от идеальных [Сайбель, Каширская 2017]. Сейчас актуальна проблема согласования интересов государства и бизнеса, при этом особенно остро эта проблема заметна на фоне взаимодействия государственной власти субъектов РФ и регионального предпринимательства.

Органы государственной власти субъектов РФ в большей степени заинтересованы в том, чтобы находить точки соприкосновения и тесного сотрудничества с региональной деловой элитой, чем федеральный центр. Это обусловлено тем, что региональные органы государственной власти в большей степени осведомлены о состоянии экономического развития собственного региона и проблемных местах в этом развитии, чем федеральные органы государственной власти, в связи с чем способны принимать адекватные и взвешенные решения, направленные на поддержку и развитие как малого и среднего предпринимательства, так и крупных предприятий. Результатом таких решений становятся программы социально-экономического развития субъектов, в рамках которых предусматриваются отдельные направления, связанные с поддержкой малого и среднего предпринимательства. Сейчас практически во всех субъектах РФ приняты такие программные документы, а в большинстве субъектов действуют отдельные государственные региональные программы поддержки малого и среднего предпринимательства. Иногда поддержка малого и среднего предпринимательства в субъектах принимает форму подпрограммы. Например, в Иркутской обл. с 2019 г. действует подпрограмма «Поддержка и развитие малого и среднего предпринимательства в Иркутской области» на 2019-2024 гг. 
государственной программы Иркутской области «Экономическое развитие и инновационная экономика на 2019-2024 годы».

В рамках региональных государственных программ становится возможным выделить ключевые приоритеты развития предпринимательства и поддерживать предпринимательские инициативы точечно, например, поддерживать фермеров или животноводов, а также тех предпринимателей, которые вовлечены в реализацию социально значимых проектов. Элементом поддержки предпринимателей выступают гранты. Например, в Республике Татарстан на поддержку начинающих фермеров выделяют до 5 млн руб., в Санкт-Петербурге действует программа поддержки предпринимателей, которые создают детские центры, а также программа поддержки предпринимателей, занимающихся ремесленничеством.

Однако ресурсные и финансовые возможности регионов не одинаковы. В силу диспропорции социально-экономического развития регионов и существования дотационных регионов не все субъекты РФ могут позволить выделять финансовые ресурсы на поддержку и развитие предпринимательства. В этой связи следует заострить внимание на проблеме неравного экономического развития регионов. В некоторых регионах России предпринимательские инициативы региональной властью поддерживаются недостаточно. Примером тому может, например, служить Республика Тыва. В 2019 г. республиканский бюджет профинансировал государственную поддержку предпринимательства в Республике Тыва. Эти средства в основном направлены на развитие сельскохозяйственного производства, однако не хватает инструментов реальной поддержки в виде субсидий на техприсоединение, оплату части лизинга, субсидирование части приобретаемого оборудования и т.д. ${ }^{1}$ Большая часть расходов финансируется из федерального бюджета в рамках государственных программ поддержки малого и среднего предпринимательства. На данном примере видно, что проблема дотационных регионов заключается в отсутствии как финансовых, так и ресурсных возможностей для поддержки деловой активности.

Но государственная поддержка является хотя и преобладающей, но не единственной формой взаимодействия региональной государственной власти и бизнеса. Взаимодействие власти и бизнеса осуществляется в самых разных формах - от прямых контрактов на предоставление услуг и выполнение работ до государственно-частного партнерства (ГЧП $)^{2}$. При этом ГЧП становится перспективной формой взаимодействия бизнеса и региональной власти, поскольку позволяет региональной власти привлекать частные инвестиции для финансирования социально значимых проектов.

Между тем, невзирая на положительные аспекты взаимодействия региональной власти и бизнеса, существуют отдельные нерешенные проблемы в этой области (см. рис. 1).

Рассмотрим кратко эти проблемы.

Финансово-кредитная и налоговая политика, бесспорно, являются ключевым инструментом воздействия на бизнес, однако малые и средние предприятия в большинстве своем не получают льготные кредиты по причине их малодоступности и высоких процентных ставок. В этом плане актуально выделение из региональных бюджетов субсидий, которые будут направлены как на

\footnotetext{
1 Информация о развитии малого и среднего предпринимательства в Республике Тыва. Доступ: http://mert.tuva.ru/directions/entrepreneurship/ (проверено 30.12.2019).

2 Приложение к Среднесрочной программе социально-экономического развития России до 2025 г. «Стратегия роста» (программа разработана в рамках поручения Президента РФ от 14 июля 2016 г. №Пр-1347). Доступ: http://stolypinsky.club/ (проверено 30.12.2019).
} 


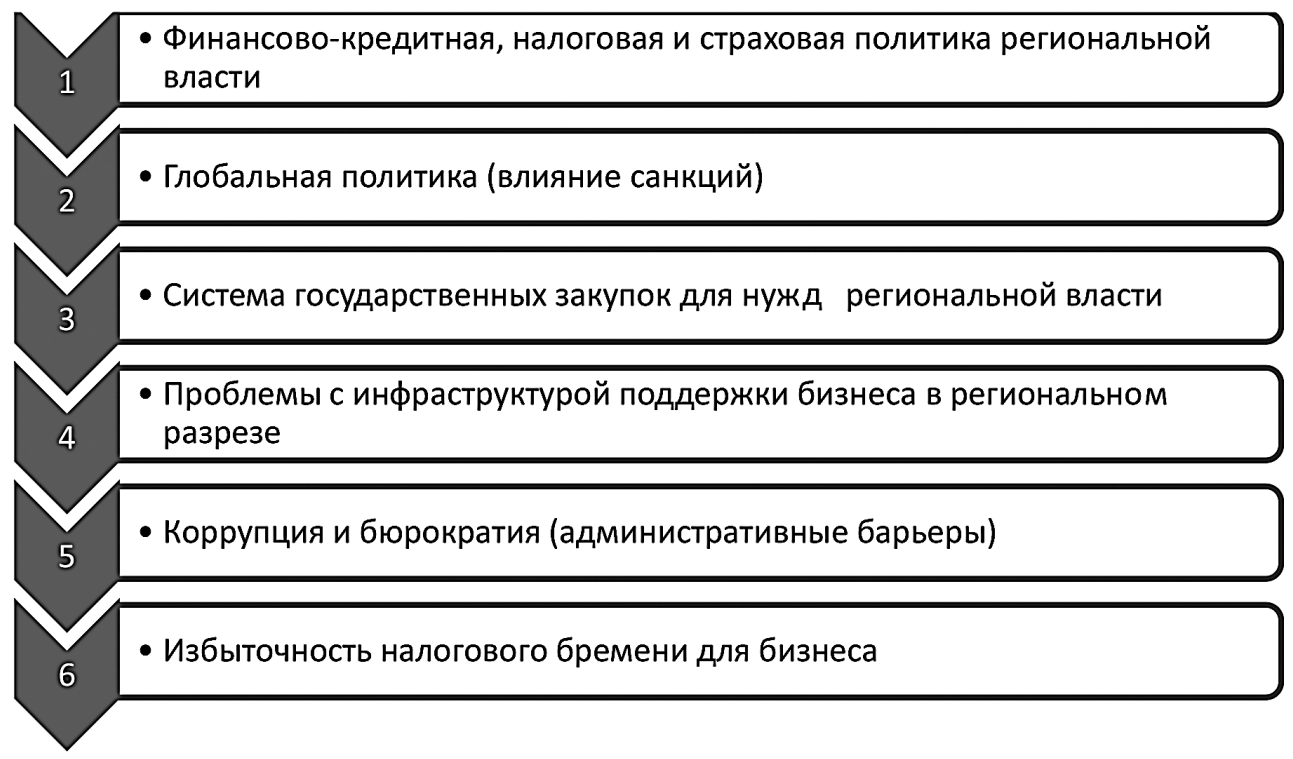

Рисунок 1. Проблемы взаимодействия бизнеса и региональной власти [Шарыгин, Кротов 2015]

компенсацию части процентной ставок по кредитам, так и на открытие нового бизнеса, расширение и модернизацию производства. Перспективным направлением региональной поддержки может стать использование налоговых каникул или льготных условий страхования для уязвимых категорий малых предприятий, осуществляющих например, научные разработки, для самозанятых граждан, а также сельскохозяйственных предприятий.

Развитию бизнеса в субъектах РФ препятствует режим санкций со стороны США, Евросоюза и примкнувших к ним стран. Ответные санкции со стороны российского руководства также сказались на развитии регионального бизнеса. Предпринимателям в регионах трудно действовать в условиях экономической неопределенности, нестабильности внешних условий и снижения курса рубля. С другой стороны, запрет на ввоз сельскохозяйственной продукции из некоторых стран Евросоюза благоприятно сказался на развитии сельскохозяйственного производства в регионах. На фоне сложной политической ситуации в мире региональной власти приходится активно участвовать в обеспечении продовольственной безопасности субъектов РФ.

Взаимодействие между бизнесом и региональной властью осуществляется в рамках государственных закупок для нужд органов государственной власти субъектов РФ. Бесспорно, вовлечение бизнеса в контрактную систему направлено, прежде всего, на решение проблем не только самого бизнеса, но всего региона в целом. Между тем в ходе самих торгов наиболее часто выявляются такие проблемы, как непоследовательность доступа к информации о закупке; отсутствие конкуренции (или образование сговора в результате неадекватности цен); конфликт интересов; отсутствие доступа к информации по выбору победителя. Среди проблем на заключительной стадии обращают на себя внимание такие проблемы, как недостаточный контроль исполнения заключенного контракта; непрозрачность выбора (или отсутствие подотчетности организаций-субподрядчиков); отсутствие инспектирования (или двойственность обя- 
занностей работников); отсутствие контроля системы оплаты госзаказа. Для успешного преодоления проблем государственных закупок, в т.ч. коррупции, и для достижения эффективного использования бюджетных средств крайне важна институциональная среда государственных закупок, в первую очередь формирование адекватной структуры и системы управления, повышение качества управления государственными ресурсами.

Развитие бизнеса во многом определяется не размером финансовых средств, которые направляются на поддержку предпринимательских инициатив, а тем, как развита инфраструктура такой поддержки. Малые предприятия всецело зависят от конъюнктуры рынка и нуждаются во всемерной поддержке. В силу значительной территориальной дифференциации регионов бизнес может оказаться в такой ситуации, когда государственная поддержка до него не доходит или доходит в незначительных объемах. Важным элементом инфраструктуры поддержки бизнеса в регионах выступают бизнес-инкубаторы. Следует отметить, что, по данным исследования, деятельность бизнес-инкубаторов преимущественно направлена на развитие и поддержку именно малого бизнеса (см. рис. 2)

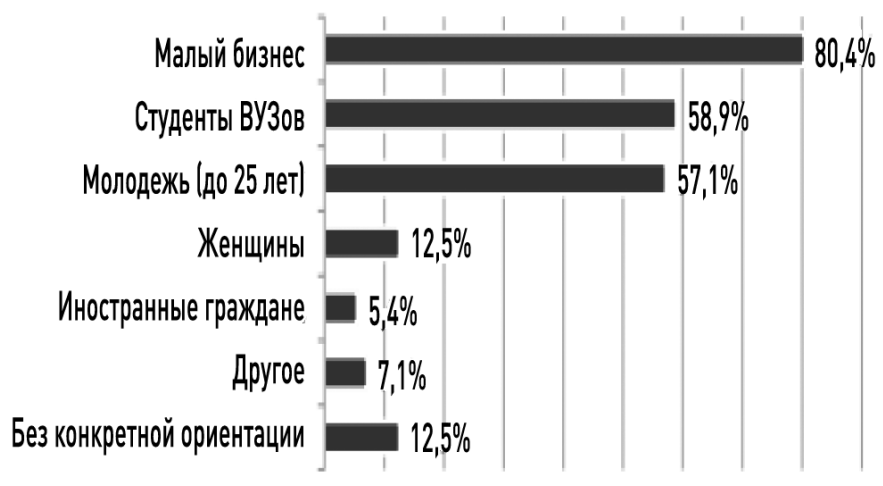

$0 \% \quad 10 \% \quad 20 \% \quad 30 \% \quad 40 \% \quad 50 \% \quad 60 \% \quad 70 \% \quad 80 \% \quad 90 \%$

Рисунок 2. Социальная ориентация российских бизнес-инкубаторов, в \% от числа респондентов

Сотрудничеству бизнеса и региональной власти препятствуют такие негативные явления, как коррупция и административные барьеры. Переход на цифровую экономику и упрощение регистрационных и контрольно-надзорных процедур должно в значительной степени снизить воздействие данного негативного фактора и предотвратить распространение коррупции в региональной политической элите.

По данным аналитиков, Россия входит в группу стран с наиболее высокой налоговой нагрузкой (на 7,2 п.п. выше, чем в среднем по миру). Общая налоговая нагрузка включает в себя налог на прибыль, налог на фонд оплаты труда, прочие налоги. По данным исследований $p w c$, в России общая налоговая нагрузка в 2007-2016 гг. снизилась с 51,4\% до 47,4\%, при этом нагрузка на ФОТ выросла на 4,3 п.п. и достигла $36,1 \%$. В среднем по миру за этот период налоги на труд сократились с $18,2 \%$ до $16,3 \% 1$ (см. рис. 3 ).

\footnotetext{
${ }^{1}$ Приложение к Среднесрочной программе социально-экономического развития России до 2025 г. «Стратегия роста».
} 


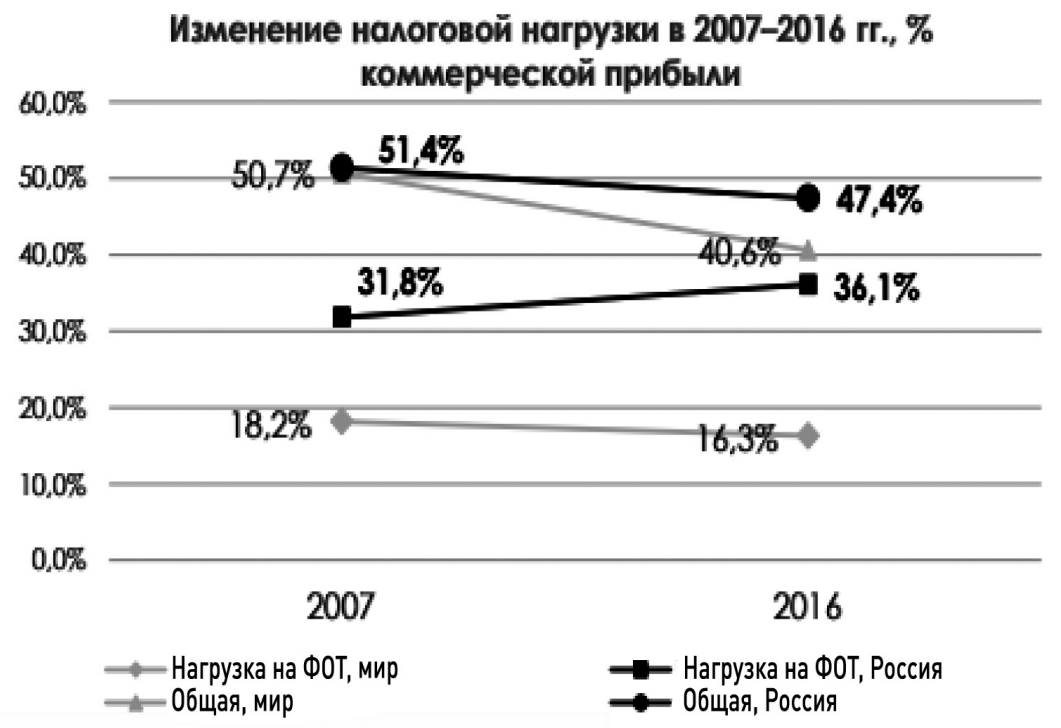

Рисунок 3. Сравнение налогового бремени в России и в мире

Избыточность налогового бремени для России - проблема, которая затрудняет правомерное использование оптимизации налогообложения в отношении российских организаций.

Бесспорно, формирование подобных рейтингов играет значимую роль при определении предпринимателем места для ведения своей хозяйственной деятельности. Региональные власти должны принимать активное участие в предоставлении объективных и достоверных сведений об условиях для малого бизнеса рейтинговым агентствам.

Показателем эффективности взаимодействия региональной власти и бизнеса является такой показатель, как инвестиционная привлекательность регионов. Здесь мы также наблюдаем значительные диспропорции, поскольку наиболее привлекательными регионами в инвестиционном плане остаются федеральные центры (г. Москва и г. Санкт-Петербург), остальные субъекты РФ не получают должного объема финансирования из федерального бюджета, а инвестиционная привлекательность регионов зависит от ресурсного или промышленного потенциала региона. Например, в 2019 г. лишь 62 субъекта РФ могли похвастаться экономическим ростом.

Перечень приведенных выше проблем взаимодействия малого предпринимательства и региональной власти не является исчерпывающим. Вместе с тем признание этих проблем властями субъектов РФ будет способствовать изменению отношения малого бизнеса к управленческим структурам и выстраиванию между ними более совершенных форм взаимодействия.

\section{Список литературы}

Сайбель Н.Ю., Каширская О.О. 2017. Особенности взаимодействия бизнеса и власти в условиях кризиса в России. - Молодой ученый. № 2. С. 496-500.

Шарыгин М.Д., Кротов И.И. 2015. Малое предпринимательства и региональная власть: проблемы отношений. - Современные проблемы науки и образования. № 1-1. Доступ: http://science-education.ru/ru/article/view?id=18006 (проверено 08.01.2020). 
KIPKEEV Taulan Muratovich, postgraduate student at the Department of Political Science and Mass Communication, Financial University under the Government of the Russian Federation (49 Leningradsky Ave, Moscow, GSP-3, Russia, 125993; kipkeev_finuniversitet@mail.ru)

\section{INTERACTION BETWEEN GOVERNMENT AND BUSINESS IN MODERN RUSSIA: ANALYSIS OF PRACTICES OF CONSTITUENT ENTITIES OF THE RUSSIAN FEDERATION}

\footnotetext{
Abstract. The article discusses the features and forms of interaction between government and business in the regional aspect. The author reveals the perspective directions on development of forms of interaction of the regional power and business.

Keywords: business, business incubator, state program, public-private partnership, public procurement, corruption, small and medium-sized business, tax burden
}

\section{УДК 324(045)}

ПЕЧЕНКИН Николай Михайлович - магистрант факультета социологии и политологии Финансового университета при Правительстве РФ (125993, Россия, г. Москва, ГСП-3, Ленинградский np-кm, 49; nick_pechyonkin@mail.ru)

\section{ДИНАМИКА ОБЩЕСТВЕННО-ПОЛИТИЧЕСКИХ НАСТРОЕНИЙ И АНАЛИЗ РЕЗУЛЬТАТОВ ВЫБОРОВ РЕГИОНАЛЬНОГО УРОВНЯ 2018-2019 гг. В ХАБАРОВСКОМ КРАЕ}

Аннотация. В статье представлены данные исследования динамики общественно-политических настроений и анализ результатов выборов регионального уровня 2018-2019 гг. в Хабаровском крае. В 2019 г. в данном регионе было проведено социологическое исследование, позволившее определить причины формирования протестных общественно-политических настроений. Для анализа выборов регионального уровня использованы результаты выборов губернатора Хабаровского края в 2018 г. и результаты выборов депутатов Законодательной думы Хабаровского края в 2019 г. Для сравнения рассмотрены выборы мэра Хабаровска в 2018 г. (один из нескольких городов в России, где мэра выбирают прямым голосованием) и выборы депутатов Хабаровской городской думы в 2019 г. По итогам исследования определены особенности формирования протестных общественно-политических настроений жителей Хабаровского края и тенденции их влияния на результаты выборов регионального уровня («протестное голосование»), а также причины поражения предыдущего губернатора В. Шпорта и победы нового губернатора С. Фургала, причины падения результатов «Единой России» и победы ЛДПР.

Ключевые слова: общественно-политические настроения, протестное голосование, выборы губернатора региона, выборы депутатов регионального парламента, поражение кандидата и партии власти, победа оппозиционного кандидата и партии

A ктуальность исследования обусловлена тремя ключевыми положениями. Во-первых, электоральный цикл 2018 г. сразу в нескольких регионах России характеризуется динамикой общественно-политических настроений граждан от лоялистских к протестным, что повлияло на результаты выборов региональ- 